\title{
STUDY OF RISK FACTORS, CLINICAL PROFILES AND ANGIOGRAPHIC PATTERNS IN PATIENTS OF CORONARY ARTERY DISEASE IN A TERTIARY CARE CENTRE IN CHHATTISGARH
}

\author{
Bajarang Lal Bansal'1, Akshata P. J2 \\ ${ }^{1}$ Consultant Cardiologist and Ex-Assistant Professor, FEHIRC, PTJNMMC, Raipur. \\ ${ }^{2}$ Fellow, Department of Internal Medicine, PTJNMMC, DRBRAMH, Raipur.
}

\section{ABSTRACT}

\section{BACKGROUND}

Deaths due to Cardiovascular Disease (CVD) accounted for 30.8\% of all deaths, i.e. 18.1 million deaths by 2010 and estimated to be $32.5 \%$ of all deaths, i.e. 24.2 million deaths by 2030 globally. In 2000, there were an estimated 29.8 million people with cardiovascular disease in India out of a total estimated population of 1.03 billion or a nearly $3 \%$ overall prevalence. It is estimated that there were approximately 46.9 million people with cardiovascular disease in India during 2010, of which 2.33 million people succumbed. Considering the increasing burden of atherosclerotic disease and its mortality and also the usefulness of finding risk factors, studying the clinical profile and angiographic pattern will help us to fight the progression of the disease by intervening at various levels which can decrease the morbidity and mortality due to cardiovascular disease.

\section{MATERIALS AND METHODS}

The present study was conducted in the Department of Medicine, Dr. B.R.A.M Hospital during the period of 2014 - 2016 . This is a hospital-based observational prospective study with prospective data collection, where all patients of coronary artery disease () who had undergone coronary angiography has been taken into consideration to find out the risk factors, clinical profiles and angiographic patterns in coronary artery disease patients in Chhattisgarh.

\section{RESULTS}

Maximum patients were present in the age group of 41 - 50 yrs., mean age being 55 years \pm 12.11 sd. Male patients were $79.4 \%$ and $20.58 \%$ were female patients. The most common symptom was chest pain, $82.35 \%$ patients had it at the time of presentation. The next frequent symptom was breathlessness, 53.92\% patients had it; $42.15 \%$ patients had sweating and $24.5 \%$ patients had palpitations. Among the risk factors, $41.1 \%$ had hypertension and $33.3 \%$ had sedentary lifestyle. On examination $61.7 \%$ patients had obesity defined by BMI > 25 and a total of $41.1 \%$ patients had hypertension; 24 patients had ABI $<0.9$ indicating PAD i.e. $23.52 \%$ in the study had PAD as visualised by CAG, 39.2\% patients had SVD, 20.58\% patients had DVD and 14.7\% had TVD; $8.8 \%$ patients had non-significant coronary artery disease; $16.66 \%$ patients had recanalised epicardial coronaries. Among 40 patients of SVD, 2 (5\%) had $\mathrm{ABI}<0.9$. Among 21 patients of DVD, $11(47.6 \%)$ had $\mathrm{ABI}<0.9$. Among 15 patients of TVD, $12(80 \%)$ had $\mathrm{ABI}<0.9$. None of the patients with non-significant coronary artery disease and normal coronaries had ABI < 0.9 . LAD was involved in 49 patients ( $48.2 \%$ ), RCA was involved in $30(29.2 \%)$ patients and LCX was involved in $20(19.6 \%)$ patients. The frequency of LAD involvement was maximum followed by RCA and then LCX; 24 (100\%) patients who had ABI $<0.9$ also had angiographic proven coronary artery disease. Of 78 patients who had $\mathrm{ABI}>0.9,52(66.7 \%)$ patients had significant coronary artery disease. Of 76 patients of significant coronary artery disease, $24(31.5 \%)$ patients had $\mathrm{ABI}<0.9$.

\section{CONCLUSION}

Coronary artery disease, an epidemic in our country has to be tackled by preventing at each step, i.e. at the level of risk factors so that the morbidity and mortality of the disease can be curtailed.

\section{KEYWORDS}

Risk Factors, Coronary Artery Disease, Coronary Angiography.

HOW TO CITE THIS ARTICLE: Bansal BL, Akshata PJ. Study of risk factors, clinical profiles and angiographic patterns in patients of coronary artery disease in a Tertiary Care Centre in Chhattisgarh. J. Evolution Med. Dent. Sci. 2016;5(104):7638-7648, DOI: 10.14260/Jemds/2016/1724

\section{BACKGROUND}

In developed countries, atherosclerotic disease is a major health problem and is a leading cause of morbidity and mortality. The incidence of coronary artery disease, an

Financial or Other, Competing Interest: None.

Submission 08-12-2016, Peer Review 20-12-2016,

Acceptance 22-12-2016, Published 29-12-2016.

Corresponding Author:

Dr. Bajarang Lal Bansal,

Consultant Cardiologist and Ex-Assistant Professor,

FEHIRC, PTJNMMC,

Raipur.

E-mail: blbansal2002@gmail.com

DOI: $10.14260 /$ jemds/2016/1724

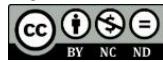

epidemic in India has doubled during past three to four decades and soon will emerge as the single largest disease accounting for nearly one-third of all deaths in India.

CVD deaths accounted for $30.8 \%$ of all deaths i.e. 18.1 million deaths by 2010 and estimated to be $32.5 \%$ of all deaths i.e. 24.2 million deaths by 2030 globally. In 2000 , there were an estimated 29.8 million people with CVD in India out of a total estimated population of 1.03 billion or a nearly $3 \%$ overall prevalence. It is estimated that there were approximately 46.9 million people with CVD in India during 2010, of which 2.33 million people succumbed.

Atherosclerotic events are the basic pathophysiological process that causes a wide manifestation of clinical syndromes from chronic stable angina to acute myocardial infarctions. It 
is the most common cause of mortality and morbidity worldwide. It is considered a generalised process affecting coronary, cerebral and peripheral arteries of lower extremities.

Amongst the various risk factors known to cause coronary artery disease are diabetes mellitus, hypertension, age, smoking, alcohol, gender, obesity, low ankle brachial index, homocysteinaemia, increased carotid intimal medial thickness, hyperlipoproteinaemia.

Considering the increasing burden of atherosclerotic disease and its mortality and also the usefulness of finding risk factors, studying the clinical profile and angiographic pattern will help us to fight the progression of the disease by intervening at various levels, which can decrease the morbidity and mortality due to cardiovascular disease.

\section{Review of Literature}

Global Burden of CVDs

Life expectancy at birth has increased from a global average of 46 years in 1950 to 66 years in 1998(1) and 71.4 yrs. in 2015.(2) With industrialisation, the epidemiologic transition has taken place and the major disease now-a-days are CVS disease."(3) This occurs not only between different disease categories, but also within a specific disease category. $(4,5)$ CVDs are a group of disorders of heart and blood vessels including coronary artery disease, peripheral vascular disease, rheumatic heart disease, congenital heart disease, deep venous thrombosis and pulmonary embolism.(6)

They are the most common cause of death globally. An estimated 17.5 million people died from CVDs in 2012, representing $31 \%$ of all global deaths. Of these deaths, an estimated 7.4 million were due to coronary artery disease and 6.7 million were due to stroke (7); 38 million of the 56 million global deaths in 2012 were due to NCDs. Premature NCD mortality of $48 \%$ occurred in $<70$ yrs. ${ }^{(8)}$

\section{Growing Burden of CVD's in Developing Countries}

The World Health Report 1999 estimates that in 1998, 78\% of the burden of NCDs and $85 \%$ of the CV burden arose from the low and middle income countries with $\mathrm{CV}$ deaths accounting for $34 \%$ of all deaths in women and $28 \%$ in men.(9) About half of the deaths attributable to CVD in developing countries in 1990 occurred $<70$ years, in contrast to about a quarter in the developed countries. $(10)$

\section{CVD in India}

Mortality data from the Registrar General of India shows CVDs are the major cause of death in India now, i.e. $40 \%$ of deaths in urban and $30 \%$ in rural areas. The adult prevalence has increased in urban areas from about $2 \%$ in 1960 to $6.5 \%$ in $1970,7.0 \%$ in $1980,9.7 \%$ in 1990 and $10.5 \%$ in 2000 ; while in rural areas it increased from $2 \%$ in 1970 , to $2.5 \%$ in $1980,4 \%$ in 1990 and $4.5 \%$ in 2000 i.e. about 30 million coronary artery disease patients in the country. The disease occurs at a much younger age in Indians. Rural-urban differences reveal that risk factors are more in urban areas.(11)

\section{Coronary Arterial Circulation (Fig. B)}

From the right and left aortic sinuses arise the right and left coronary arteries respectively and their ostia, which normally originate about two-thirds the distance from the aortic annulus to the sinotubular junction and about midway between the aortic commissures.[12-14] It supplies the cardiac tissue, conduction tissue, etc. The artery that crosses the cardiac crux and gives rise to the posterior descending branch represents the dominant coronary artery. Dominance is right in $70 \%$ of human hearts, left in $10 \%$ and shared in $20 \%$.[12-14] Coronary Arteriography (CAG) remains the standard for identifying arterial narrowings related to atherosclerotic coronary artery disease. First performed by Sones in 1959, CAG has subsequently become one of the most widely used invasive procedures in cardiovascular medicine.[15]

\section{Angiographic Assessment of Coronary Artery Narrowings (Fig. C)}

An angiographic lumen narrowing is commonly referred to as a stenosis, which may be caused by atherosclerosis, vasospasm or angiographic artifact. The diameter of stenosis is calculated in the projection where the greatest narrowing is seen.

\section{Angiographically Estimated Coronary Blood Flow (TIMI Flow)}

Qualitative myocardial blood flow is assessed using Thrombolysis in Myocardial Infarction (TIMI) score (TIMI 0 3) for qualitative grading of coronary flow. In acute MI trials, TIMI Grade 3 flows have been associated with improved clinical outcomes.[16]

\section{Conventional Risk Factors[17]}

- Smoking.

- Hypertension.

- Hyperlipidaemia and Elevated Low-Density Lipoprotein Cholesterol.

- High-Density Lipoprotein Cholesterol, Apolipoproteins, and Other Lipid Subclasses.

- Triglyceride-Rich Lipoproteins.

- Metabolic Syndrome, Insulin Resistance and Diabetes.

- Exercise, Weight Loss and Obesity.

- Mental Stress, Depression and Cardiovascular Risk.

\section{Novel Atherosclerotic Risk Markers[17]}

- High-Sensitivity C-Reactive Protein.

- Other Markers of Inflammation.

- Homocysteine.

- Lipoprotein (a).

- $\operatorname{Low} \mathrm{ABI}(<0.9)$.

\section{Hypertension}

Worldwide, approximately $62 \%$ of strokes and $49 \%$ of cases of coronary artery disease are attributable to suboptimal ( $>115$ mmHg systolic) blood pressure, accounts for more than 7 million deaths annually. Lawes and Vander et al[18] estimated that $14 \%$ of deaths and $6 \%$ of DALYs lost globally were caused by non-optimal levels of blood pressure.

Pulse pressure reflecting vascular wall stiffness predicts first and recurrent MI and also CVEs independently, particularly heart failure.[19] Bobrie et al,[20] Ingelsson et al study[21] also supported the detrimental effect of hypertension on CVS disease.

Blood pressure reductions as small as 4 to $5 \mathrm{mmHg}$ result in large and clinically significant reductions in cardiovascular risk.[22] In Law and Associates analysis of 354 randomised trials, regimens of multiple drugs given were estimated capable of reducing SBP by $20 \mathrm{mmHg}$ and DBP by $11 \mathrm{mmHg}$, 
effects that could result in reductions of stroke by $63 \%$ and CHD by $46 \%$.[23]

\section{Smoking}

Other than advanced age, smoking is the single most important preventable risk factor for coronary artery disease. Ezzati and co-workers ${ }^{[24]}$ have calculated that in 2000 more than 1.62 million CVD deaths worldwide or $11 \%$ of the total were caused by smoking; 1.17 million were men and 670,000 occurred in the developing world. The combined use of different forms of tobacco is associated with a higher risk of MI than using one type.[25,26]

Barnoya and Glantz ${ }^{[27]}$ found that second-hand smoke is associated with 1.31-fold increased risk of CHD. Smoking prevalence is more in men and increases with age.[28] Critchley and Capewell study showed smoking cessation reduced CHD mortality by $36 \% .{ }^{[29]}$

\section{Lipids}

Worldwide, high cholesterol levels cause $56 \%$ of IHD and $18 \%$ of strokes amounting to 4.4 million deaths annually. The Heart Protection Study showed that statins can reduce stroke and coronary events in those with pre-existing vascular disease.[30] As a group, placebo-controlled trials of statins lowered LDL cholesterol levels by $20 \%$ to $60 \%$ and reduced coronary events by one-third over a 5-year period with no evidence of an increase in nonvascular mortality.

Menotti et al[31] cited that Low HDL-cholesterol $(<42$ $\mathrm{mg} / \mathrm{dL}$ ) is the strongest predictor of subsequent CVEs (3.3 fold higher risk). In general, increase of HDL cholesterol by 1 $\mathrm{mg} / \mathrm{dL}$ is associated with a $2 \%$ to $3 \%$ decrease in risk of total CVD.

Pischon et al[32] in men and Ridker et al[33] suggested that the measurement of apolipoproteins A-I and B100 would predict cardiovascular risk better than HDL and LDL cholesterol in clinical practice and also total cholesterol-toHDL-C ratio remained a very strong predictor, superior even to apolipoprotein B100 to A-I.

Hypertriglyceridaemia is associated with several atherogenic factors and substantially increase the risk of CVD (KU-Leuven and Department of Clinical Chemistry, Belgium). Bansal et al[34] and Nordestgaard et al[35] have recently reported that non-fasting TAGs predict vascular events, independent of traditional risk factors, but that fasting TAG levels show little independent relationship.[34,35] On this basis, prediction of vascular risk may need to be based on an oral triglyceride tolerance test, analogous to a glucose tolerance test used to diagnose diabetes.[36]

\section{Diabetes, Metabolic Syndrome and Insulin Resistance}

Booth et al[37] stated the presence of diabetes conferred an equivalent risk to aging 15 years, an impact higher than that of smoking. Patients with diabetes have two- to eight-fold higher rates of future CVEs and $75 \%$ of all deaths in diabetic patients result from CHD.

Diabetes mellitus affects approximately 180 million people worldwide, which may rise to double by 2030.[38] Interestingly, Asian countries like India and China have the largest numbers of diabetics - 32 million and 21 million, respectively in the world[39] due to greater visceral obesity despite lean body weight.
Insulin resistance itself promotes atherosclerosis even before it produces frank diabetes, which has prompted recommendations for increased surveillance for the metabolic syndrome.

\section{Obesity}

According to the latest WHO data, there are approximately 1.1 billion overweight adults in the world with 115 million of them known to be living with obesity-related problems.[40] Popkin and Gordon-Larsen[41] have reported that use of edible oils, caloric sweeteners and animal source foods is increasing. Women are more affected than men with the number of overweight women generally exceeding underweight women based on data from 36 developing countries. ${ }^{[42]}$ Adolescents are at particular risk with 1 in 10 children currently estimated to be overweight. [41,43]

\section{Physical Inactivity}

Manson et al showed in both men and women, exercise levels achieved with as little as 30 minutes of walking daily provide major cardiovascular benefits. [44]

Aerobic exercise is associated with a mean reduction of SBP of $5 \mathrm{mmHg}$ in hypertensive participants. Exercise consistently improves HDL-C and reduces TAG levels. Exercise further improves insulin sensitivity and glycaemic control with major benefits for diabetic patients including reductions in glycated haemoglobin and reduced requirements for therapy.

\section{Diet}

A key element of dietary change is an increase in intake of saturated animal fats and inexpensive hydrogenated vegetable fats, which contain atherogenic trans fatty acids leading to abdominal obesity, another risk factor for CVD. Another facet of adopting a Western diet is the introduction of soft drinks and other high-sugar beverages, which is associated with weight gain and increased risk of type 2 diabetes.[45]

\section{Population Aging}

Average life expectancy will reach 73 years by 2025, according to the WHO. The time of transition to an older population is markedly shorter in developing countries. The United States and Canada took more than 65 years to double their over- 65 population, but China will do so in 26 years, Tunisia in 24 and Brazil in 21.[46] Such acute changes in the population structure leave less time to expand an already overburdened health infrastructure to address chronic diseases of older adults, prominently cardiovascular conditions.

\section{Mental Stress, Depression and Cardiovascular Risk}

The adrenergic stimulation of mental stress can augment myocardial oxygen requirements, aggravate myocardial ischaemia, cause coronary vasoconstriction, particularly in atherosclerotic coronary arteries, platelet and endothelial dysfunction and ventricular arrhythmias. Work related stress has two components - job strain and effort-reward imbalance, both doubling risk for MI and stroke.[47]

In the Inter-Heart Study evaluating post-infarction patients from 52 countries, psychosocial stress was associated with vascular risk with a magnitude of effect similar to that of the major coronary risk factors. [48] In patients with stable IHD and exercise-induced myocardial ischaemia, random 
allocation to a stress management program reduced emotional distress and improved biomarkers of vascular risk significantly.[49] In South Asia of all, the low- and middleincome regions have the highest prevalence of diabetes. In 2006, Goyal and Yusuf[50] estimated that the prevalence was $3.8 \%$ in rural areas and $11.8 \%$ in urban areas. Similarly, IC Health reported a prevalence of $14 \%$ in an Indian urban setting in 2000.[51] According to the Inter-Heart study, 11.8\% of all MIs in the South Asia region result from diabetes. [52]

According to Goyal and Yusuf,[50] data from 2004 have shown that hypertension affects $20 \%$ to $40 \%$ of urban residents and $12 \%$ to $17 \%$ of rural residents. This is an estimated total of 118 million people in India.[50] Inter-Heart study found a prevalence for hypertension of 19.3\% attributable to MI.[52] Goyal[50] has reported that of those between the ages of 12 and $60,56 \%$ used tobacco.

The IC Health report identified overweight and obesity as a growing issue in Indian populations. In Northern India, prevalence measured by waist circumference soared from $33.2 \%$ to $45 \%$ in 2001 and 2003, respectively. Urban South Asia had high waist-to-hip ratios as well, increasing 16\% (63\% to $79 \%$ ) between 2001 and 2003. In 2000, the prevalence as measured by BMI was 31\% in those aged 20 to 40 and $38 \%$ in those older than 40 years in seven urban cities. The rate from the same study measured by waist circumference was 32\%.[53] According to Inter-Heart, abdominal obesity accounts for $37.7 \%$ of MI cases.[52]

In addition to factors already mentioned, the Inter-Heart study reported low intake of fruits and vegetables accounts for $18.3 \%$ of MI, lack of exercise $27.1 \%$ and lipids $58.7 \%$. In total, all nine risk factors explain $89.4 \%$ of all causes of MI.[52]

\section{RESULTS AND DISCUSSION}

\section{Age and Sex Wise Analysis of Patients Suspected of Coronary Artery Disease}

In our study, mean age is 55 years $+12.11 \mathrm{sd}$. We had $30.39 \%$ patients present in the age group of $41-50$ yrs., $27.45 \%$ patients were present in the age group $51-60$ yrs., 22 patients were present in the age group 61 - 70 yrs., $11.76 \%$ patients were present in age group > 70 yrs., 6.86\% patients were present in age group 31 - 40 yrs., $1.96 \%$ patients were present in age group $</=30$ yrs.; maximum number were male patients, i.e. 81 (79.4\%) out of 102 patients; 21 (20.6\%) were female patients. The Table 3 shows in all the age groups, male patients were more than female patients. Mean age in males is 54.39 years $+12.27 \mathrm{sd}$. Mean age for females is 54.54 years + $12.27 \mathrm{sd}$.

Hazratullah, Matiullah et al, study at Punjab Institute of Cardiology, Lahore studied pattern of coronary artery disease in young adults $<40$ years and those $>40$ years with significant coronary artery disease on CAG. Out of total 400 patients, patients of age $<40$ years were $48(12 \%)$ and $>40$ years were $352(88 \%)$. There were $77 \%$ male patients and $22.5 \%$ female patients. Mean age of patients was $52.78+10.02$. Significant coronary artery disease was present in 48 $(10.75 \%)$ in patients < 40 years and $306(76.5 \%)$ in patients > 40 years. Frequency of SVD, DVD and TVD in patients $<40$ years was 24 (50\%), 10 (20.8\%), 9 (18\%) respectively, while frequency of SVD, DVD and TVD in patients $>40$ years was 98 (27\%), 88 (25\%) and 120 (34\%) respectively with p value of $0.002,0.53$ and 0.03 among SVD, DVD and TVD between the two groups. They concluded young $(<40$ years $)$ patients who have coronary artery disease have less extensive CAD with higher incidence of angiographically normal vessels and relative paucity of left main coronary artery involvement.

Ezhumalai B, Jayaraman B et al, study at Department of Cardiology, Srivenkateshwara Medical College and Hospital and JIPMER, Puducherry, India, analysed 500 women who underwent CAG for suspected coronary artery disease over 3 years and observed there was greater prevalence of obstructive coronary artery disease, especially DVD and TVD in patients $>55$ years, while normal coronaries were more prevalent in patients $<55$ years.

Manal Khudhur Abdul Razzaq, Jawad Ibrahim Rasheed et al (2013) conducted their cross-sectional study at Baghdad Teaching Hospital, during the period (May 2011 - Jan. 2012). Fifty patients without known diabetes who were admitted to the CCU with ACS were selected; out of 50 patients 37 (74\%) were male and $13(26 \%)$ were female with mean age of $(60.6$ \pm 6.3 ) year and in the range of ( 45 - 70) years.

Li-Feng Hong, Xiao-Lin Li et al conducted study enrolled 1433 consecutive women (29.7\%) and men (70.3\%), mean age is $58.3 \pm 10.2,995(69.43 \%)$ patients are non-diabetic and 438 $(30.56 \%)$ are diabetic, suggesting males are more affected with ACS. Our study also has same findings, i.e. males (81.7\%) are more affected with ACS as compared to female (18.3\%). In a study conducted by Christina Chrysohoou, Christos Pitsavos et al, 1000 ACS patients who were consecutively enrolled during 2007 - 2008, 583 (58.3\%); mean age of (63 \pm 13 years, $20 \%$ females) non-diabetic patients were studied in this work and 417 (41.7\%) were diabetic. So as per all these studies, males are affected more than female; most of the patients are of age in range of $(41-60)$ years.

\section{Analysis of Clinical Symptoms in Patients}

The Table 4 describes the major clinical symptoms, which brought the patients to hospital. Most common symptom was chest pain, 84 patients had it at the time of presentation. The next frequent symptom was breathlessness, 55 patients had; 43 patients had sweating; 25 patients had palpitations. In our study the most common symptom was chest pain, $82.35 \%$ patients had it at the time of presentation. The next frequent symptom was breathlessness, $53.92 \%$ patients had; $42.15 \%$ patients had sweating; $24.5 \%$ patients had palpitations which was similar to many studies.

\section{Analysis of Clinical Signs on General Physical Examination On general physical examination, Table 6 predicts that 10 patients had pallor, 1 had icterus. Few patients had signs of heart failure, i.e. 6 had pedal oedema and 2 had raised JVP. On general physical examination, in our study $9.8 \%$ patients had pallor, $0.98 \%$ had icterus, $9.8 \%$ patients had signs of heart failure i.e. $5.88 \%$ had pedal oedema and $1.96 \%$ had raised JVP. \\ Analysis of Risk Factors in Patients Suspected of Coronary Artery Disease \\ The above Table 5 shows various risk factors of Coronary} Artery Disease in patients. Maximum hypertension and sedentary lifestyle was found equally among patients, 34 each. Next in frequency was diabetes mellitus type II found in 29 patients; 24 patients would consume alcohol and 21 patients would smoke; 16 patients had silent MI and 16 would consume tobacco; 11 patients were on treatment for dyslipidaemia; 4 patients had family h/o MI. 
In our study of all the risk factors, hypertension (Table 7) i.e. $41.1 \%$ was found among patients (A total of 42 patients of 102 studied had hypertension); 19 patients had blood pressure recordings in the range of hypertension (as defined by JNC criteria 8 ) at the time of hospitalisation.

Table 8 predicts that 63 patients out of 102 had obesity, defined by BMI > 25. BMI calculated by weight (in kilograms)/height (in $\mathrm{cms}^{2} ; 16$ patients were overweight with BMI between 23.0 and 24.9. Sedentary lifestyle was found in $33.33 \%$, next in majority.

Diabetes mellitus type II was found in $28.43 \%$ patients; $23.52 \%$ patients would consume alcohol and $20.58 \%$ patients would smoke; $15.68 \%$ patients had silent MI and $15.68 \%$ would consume tobacco; $10.78 \%$ patients were on treatment for dyslipidaemia; $3.9 \%$ patients had family h/o MI.

The above Table 9 shows 78 patients out of 102 analysed had $\mathrm{ABI}>0.9$, i.e. normal ABI; 24 patients had $\mathrm{ABI}<0.9$ indicating Peripheral Artery Disease (PAD) i.e. $23.52 \%$ in the study had PAD.

Goldbourt U, Yaari S, Medalie JH et al, studied isolated low HDL as a risk factor for coronary artery disease mortality; 8000 men were studied in a 21-year followup. Men with isolated low HDL represented one-sixth of the cohort. CHD mortality among these men was 36\% higher (age adjusted) than in the counterparts with the desired total cholesterol. This was particularly increased in men with diabetes mellitus, whose death rates was $65 \%$ higher than in diabetics with HDL $>40 \mathrm{mg} / \mathrm{dL}$.

Joya Ghosh, TK Mishra, YN Rao, SK Aggarwal et al, at Maulana Azad Medical College, New Delhi, studied 60 aged and sex matched normal healthy individuals were taken as controls and 60 patients of coronary artery disease were taken. Serum levels of HDL, LDL, VLDL and total cholesterol were measured. It was observed that LDL, VLDL, total cholesterol, total cholesterol : HDL ratio, LDL : HDL ratio were significantly raised and HDL was significantly low in patients with $\mathrm{p}$ value $<0.001$. The levels of oxidised LDL showed an increasing trend in patients.

Weverling-Rijnsburger AW, Jonkers IJ, Van Exel E et al at Leiden University Medical Center, the Netherlands, conducted a prospective study with 599 subjects enrolled and were followed up for 4 years. Serum levels of total cholesterol, LDL and HDL were assessed as baseline and also comorbidities. During 4-year follow-up of 152 subjects died, the leading cause being CVD. Low HDL was associated with two-fold higher risk of fatal CVD (95\% CI, 1.2 - 3.2). The mortality risk of coronary artery disease was 2.0 (95\% CI, 1 - 3.9) and for stroke it was 2.6 (95\% CI, 1.0 - 6.6). The risks were unaffected by comorbidities.

Tavia Gordon, William P Castelli, Marthana C Hjortland, William B Kannel, Thomas R Dawber et al, studied HDL as a protective factor against coronary artery disease. Fasting tags, HDL, LDL and total cholesterol were obtained of 2815 men and women aged between 49 and 82 years at Framingham. In approximately 4 years following characterisation of lipids, coronary artery disease developed in 79 of 1025 men and 63 of 1445 women free of coronary artery diseases. At these older ages, major potent lipid risk factor was HDL, which had inverse association with incidence of coronary artery disease, $p$ value $<0.001$ in men and women.

Burman A, Jain K, Gulati R, Chopra V et al, at Delhi University studied 20 coronary artery disease patients and 20 healthy controls were recruited for this study. Their fasting plasma lipoprotein (a) and complete lipid profile were analysed. Results indicated plasma lipoprotein (a), total cholesterol, triglycerides, HDL, LDL and LDL : HDL ratio of coronary artery disease patients were significantly higher than the controls.

\section{Analysis of Angiographic Findings in Patients}

In our study, 40 (39.2\%) patients of 102 studied had SVD as visualised by coronary angiography; $21(20.6 \%)$ patients had DVD and 15 (14.7\%) had TVD; 9 (8.8\%) patients had nonsignificant coronary artery disease, i.e. stenosis $<75 \% ; 17$ $(16.7 \%)$ patients had recanalised epicardial coronaries.

Our study shows LAD was involved in 49 patients (48.2\%), RCA was involved in 30 (29.2\%) patients and LCX was involved in 20 (19.6\%) patients. Diagonal 1 (D1) was involved in $5(4.9 \%)$ patients, OM1 in $5(4.9 \%)$ patients and OM2 in 4 (3.9\%) patients. Recanalised vessel was seen in 6 (5.88\%) patients. LMCA was not involved in our selected study group. This suggests frequency of LAD involvement was maximum followed by RCA and then LCX.

Zhahid Hassan, Summiya Farooq, Naila Nazir et al, study conducted at SKIMS, Srinagar, J and K, India. In their study, 45 (90\%) patients were men and $5(10 \%)$ were women; $10 \%$ were obese and $78 \%$ were overweight. Smoking was present in $78 \%$ population, family history in $52 \%$ population, diabetes mellitus in $12 \%$, hypertension in $40 \%$ and hyperlipidaemia in $48 \%$ population. Angiographically, the $\%$ of coronaries involved was $84 \%(n=42)$. SVD was the most common angiographic finding in the study group; $67 \%$ of patients had SVD, 28\% had DVD and 5\% had TVD. LAD was the most commonly involved artery followed in frequency by RCA and then LCX. Findings obtained in our study were similar to this study.

Ibrahim Shah, Muhammad Faheem, Shahzeb et al, conducted study at Department of Cardiology, Lady Reading Hospital, Peshawar, Pakistan. Total of 1325 patients were included in study of which $980(73.8 \%)$ were men and mean age as $53+10.8$ years; $36 \%$ patients suffered from hypertension, $17 \%$ from diabetes mellitus, $42 \%$ had dyslipidaemia, $37 \%$ were smokers and $32 \%$ had history of premature coronary artery disease. On angiographic analysis, 251 (18.9\%) patients had SVD, 344 (26\%) had DVD, 596 (45\%) had TVD, 42 (3.2\%) had LMD and 92 (6.9\%) had normal coronaries. The involvement of LAD, LCX and RCA was $42 \%$, $26 \%$ and $32 \%$ respectively. A total of 2517 lesions were identified in which mild, moderate and severe were 276 (11\%), 327 (13\%) and 1912 (76\%) respectively. PCI was advised for 874 (66\%) and CABG for 251 (18.9\%). They concluded conventional risk factors were highly prevalent in patients of coronary artery disease. DVD and TVD was most common in these patients and PCI was frequently used treatment modality. Their findings were similar to our study findings.

Ezhumalai B and Jayaraman B et al, study at Department of Cardiology, Srivenkateshwara Medical College and Hospital and JIPMER, Puducherry, India analysed 500 women who underwent CAG for suspected coronary artery disease over 3 years and observed there was greater prevalence of obstructive coronary artery disease, especially DVD and TVD in patients $>55$ years, while normal coronaries were more prevalent in patients $<55$ years. Prevalence of left main 
disease is $3.4 \%$, obstructive coronary artery disease $45.4 \%$ and multivessel disease 28\%. The prevalence of LMD and multivessel disease is $31.4 \%$. Pattern of involvement was same between the groups.

Sreeranga PC, V Kumar Swamy, Veeranagowda et al, of Bangalore Medical College conducted a study at Jayadeva Hospital and included 263 patients between age 30 - 83 years among women who routinely underwent CAG. Angiographically determined SVD, DVD and TVD were $41 \%$, $10 \%$ and $12.5 \%$ respectively. LMCA was involved in $5 \%$ patients, recanalised vessel in $5 \%$ patients. Age $>50$ years formed $82 \%$ of their study group.

All the above studies have similar angiographic patterns as with our study.

\section{Analysis of ABI values in Subjects with different Patterns of Coronary Artery Disease}

In our study (Table 13) among 40 (39.2\%) patients of SVD, 38 $(48.7 \%)$ patients had $\mathrm{ABI}>0.9$ and $2(8.3 \%)$ had $\mathrm{ABI}<0.9$. Among 21 (20.6\%) patients of DVD 11 (14.1\%) patients had $\mathrm{ABI}>0.9$ and $10(41.7 \%)$ had $\mathrm{ABI}<0.9$. Among $15(14.7 \%)$ patients of TVD, $3(3.8 \%)$ patients had ABI > 0.9 and 12 $(50.0 \%)$ had $\mathrm{ABI}<0.9$. Patients with non-significant coronary artery disease and normal coronaries had $\mathrm{ABI}>0.9$ in 17 $(21.8 \%)$ and $9(11.5 \%)$ respectively with $0 \% \mathrm{ABI}<0.9$ in both categories.

In our study, 24 patients who had ABI $<0.9$ also had angiographic proven coronary artery disease. Of 78 patients who had $\mathrm{ABI}>0.9,52$ patients had significant coronary artery disease. Of 76 patients of significant coronary artery disease, 24 patients had $\mathrm{ABI}<0.9$. In our study, it was found that sensitivity of $A B I$ for coronary artery disease is $31.6 \%$ (21 - 43) and specificity of $\mathrm{ABI}$ for coronary artery disease is $100 \%$ (84 - $100 \%$ ). Positive predictive value of $\mathrm{ABI}$ is $100 \%$ (82 - 100) and negative predictive value of $\mathrm{ABI}$ is $33 \%$ (23 - 45). Accuracy of $\mathrm{ABI}$ for coronary artery disease was found to be 49.01 in our study.

Masoumeh Sadeghi, Ramin Heidari, Baharak Mostanfar, Ali Akbar Tavassoli et al, study conducted in Isfahan University of Medical Sciences, Isfahan, Iran. Their study included 125 patients, $85(68 \%)$ were men and $40(32 \%)$ were women aged between 32 and 80 years, suspected of coronary artery disease. Mean age of studied patients were $58.9+10.0$ years; 25 patients $(20 \%)$ of the studied population had ABI $<0.9$. Prevalence of $\mathrm{ABI}<0.9$ was $25.9 \%$ and $7.5 \%$ in men and women respectively with $\mathrm{P}$ value 0.01 . Abnormal angiographic findings were seen in $96 \%$ (24 patients) of $\mathrm{ABI}<0.9$ and $74 \%$ (74 patients) of $A B I>0.9$ with $p$ value 0.01 . In their study, they found that the prevalence of atherosclerotic risk factors was significantly higher in patients with $\mathrm{ABI}<0.9$. Patients with $\mathrm{ABI}<0.9$ had more significant stenosis than patients with $\mathrm{ABI}$ $>0.9$ and the mean occlusion was significantly higher in $\mathrm{ABI}<$ 0.9 patients with LMCA, RCA $<\mathrm{LAD}<\mathrm{LCX}$ and $\mathrm{D} 1$ involvement. They concluded that ABI could be a useful method in assessing both atherosclerotic risk factors and the degree of coronary involvements in suspected patients. These findings are similar to that obtained in our study, except that specificity is $100 \%$ much higher than their study.

Eduardo DE Papa, Izo Helber, Manes R Ehrlichmann, Claudia Maria Rodrigues Alves et al, study conducted at Department of Cardiology, Universidade Federal Do Estado De Sao Paulo, Brazil. They analysed 100 patients over 65 years of age with coronary artery disease as confirmed by CAG and with over $70 \%$ stenosis of at least one sub-epicardial coronary artery. They measured $\mathrm{ABI}$ immediately after CAG and a value $<0.9$ was used to diagnose PAD. Their results showed average age of patients was 77.4 years. The most prevalent risk factor was hypertension (96\%). The ABI $<0.9$ was seen in $47 \%$ patients and a low index was more prevalent in patients with multivessel coronary artery disease compared to patients with uniarterial disease in the same group. Using a bivariate analysis, they concluded that only an $\mathrm{ABI}<0.9$ was a strong predictive factor for cardiovascular events, thereby increasing all-cause mortality and fatal and non-fatal MI two- to threefold. They concluded that in elderly patients with documented coronary artery disease, a low ABI was associated with the severity and extent of coronary artery disease. The study findings are similar to our study.

Zinat Nadia-Hatmi, Soheila Dabiran, Ahmad SabouriKashani, Zeynab Heidarzadeh et al, conducted a study in Tehran Heart Center between 2010 and 2011, recruited 362 angiographically confirmed cases of coronary artery disease and 337 controls. They concluded that a low ABI had specificity of $99.7 \%$, however of its low sensitivity of $64 \%$, one should consider coronary artery disease risk factors associated with a low $\mathrm{ABI}$ in order to use it as a first line screening test. The findings observed in the above study are similar to our study with our study having specificity of $100 \%$.

\begin{tabular}{|c|c|c|}
\hline Age Group & Frequency & Percent \\
\hline$</=30$ & 2 & 2.0 \\
\hline $31-40$ & 7 & 6.9 \\
\hline $41-50$ & 31 & 30.4 \\
\hline $51-60$ & 28 & 27.5 \\
\hline $61-70$ & 22 & 21.6 \\
\hline$>70$ & 12 & 11.8 \\
\hline Total & $\mathbf{1 0 2}$ & $\mathbf{1 0 0 . 0}$ \\
\hline \multicolumn{2}{|c|}{ Table 1. Analysis of Age Distribution in Patients } \\
\hline
\end{tabular}

\begin{tabular}{|c|c|c|}
\hline Gender & Frequency & Percent \\
\hline Female & 21 & 20.6 \\
\hline Male & 81 & 79.4 \\
\hline Total & $\mathbf{1 0 2}$ & $\mathbf{1 0 0 . 0}$ \\
\hline Table 2. Analysis of Sex Distribution of Patients \\
\hline
\end{tabular}

\begin{tabular}{|c|c|c|c|c|}
\hline Age Group & & \multicolumn{2}{|c|}{ Gender } & Total \\
\hline & & $\mathrm{F}$ & $\mathrm{M}$ & \\
\hline \multirow{2}{*}{$</=30$} & $\mathrm{~N}$ & 1 & 1 & 2 \\
\cline { 2 - 5 } & $\%$ & $4.8 \%$ & $1.2 \%$ & $2.0 \%$ \\
\hline \multirow{2}{*}{$31-40$} & $\mathrm{~N}$ & 0 & 7 & 7 \\
\cline { 2 - 5 } & $\%$ & $.0 \%$ & $8.6 \%$ & $6.9 \%$ \\
\hline \multirow{2}{*}{$41-50$} & $\mathrm{~N}$ & 4 & 27 & 31 \\
\cline { 2 - 5 } & $\%$ & $19.0 \%$ & $33.3 \%$ & $30.4 \%$ \\
\hline \multirow{2}{*}{$51-60$} & $\mathrm{~N}$ & 8 & 20 & 28 \\
\cline { 2 - 5 } & $\%$ & $38.1 \%$ & $24.7 \%$ & $27.5 \%$ \\
\hline \multirow{2}{*}{$61-70$} & $\mathrm{~N}$ & 6 & 16 & 22 \\
\cline { 2 - 5 } & $\%$ & $28.6 \%$ & $19.8 \%$ & $21.6 \%$ \\
\hline \multirow{2}{*}{$>70$} & $\mathrm{~N}$ & 2 & 10 & 12 \\
\cline { 2 - 5 } & $\%$ & $9.5 \%$ & $12.3 \%$ & $11.8 \%$ \\
\hline \multirow{2}{*}{ Total } & $\mathbf{N}$ & $\mathbf{2 1}$ & $\mathbf{8 1}$ & $\mathbf{1 0 2}$ \\
\cline { 2 - 5 } & $\mathbf{\%}$ & $\mathbf{1 0 0 . 0} \%$ & $\mathbf{1 0 0 . 0} \%$ & $\mathbf{1 0 0 . 0} \%$ \\
\hline
\end{tabular}

Table 3. Analysis of Age and Sex Distribution of Patients 
Distribution of Risk Factors of CAD

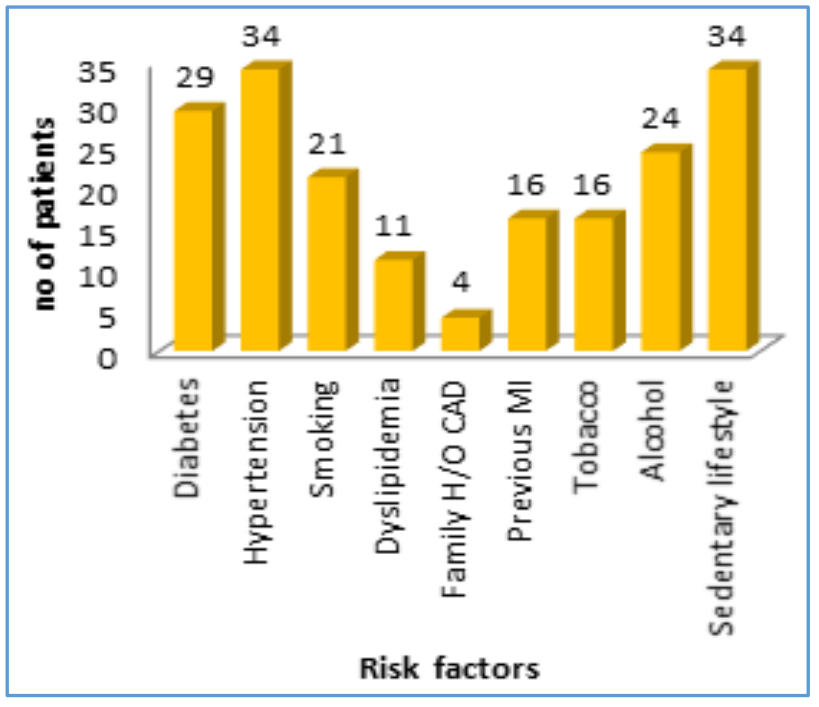

\begin{tabular}{|c|c|c|}
\hline Characteristics & Frequency & Percent \\
\hline Chest pain & 84 & 82.4 \\
\hline Breathlessness & 55 & 53.9 \\
\hline Orthopnoea & 1 & 1.0 \\
\hline PND & 4 & 3.9 \\
\hline Palpitation & 25 & 24.5 \\
\hline Syncope & 14 & 13.7 \\
\hline Sweating & 43 & 42.2 \\
\hline Angina equivalents & 21 & 20.6 \\
\hline Table 4. Distribution of Major Clinical Symptoms in \\
Patients \\
\hline
\end{tabular}

\begin{tabular}{|c|c|c|}
\hline Risk Factors & Frequency & Percent \\
\hline Diabetes & 29 & 28.4 \\
\hline Hypertension & 34 & 33.3 \\
\hline Smoking & 21 & 20.6 \\
\hline Dyslipidaemia & 11 & 10.8 \\
\hline Family H/O CAD & 4 & 3.9 \\
\hline Previous MI & 16 & 15.7 \\
\hline Tobacco & 16 & 15.7 \\
\hline Alcohol & 24 & 23.5 \\
\hline Sedentary Lifestyle & 34 & 33.3 \\
\hline Table 5. Distribution of Risk Factors of Coronary Artery \\
Disease in Patients \\
\hline
\end{tabular}

Distribution of Major Clinical Symptoms in Patients

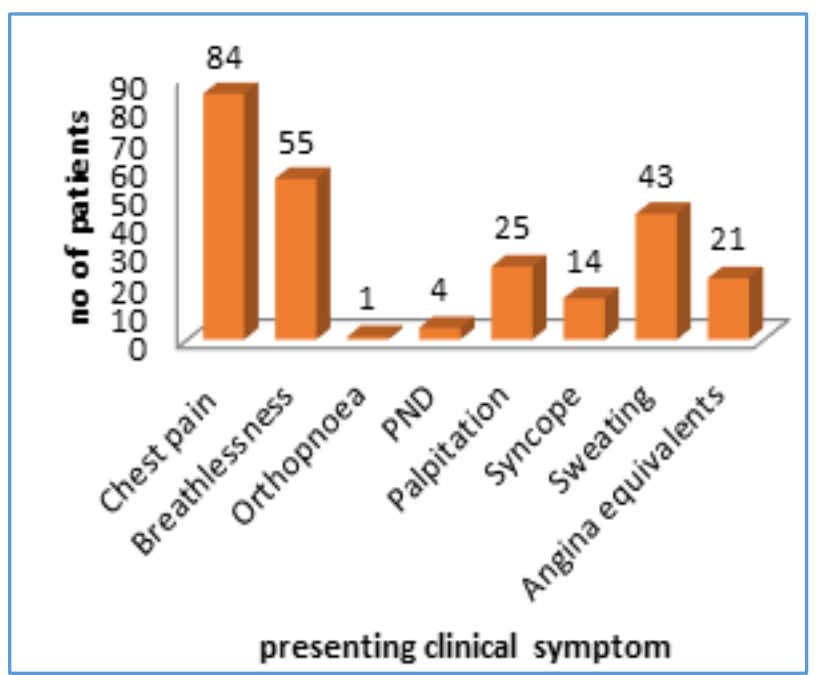

\begin{tabular}{|c|c|c|}
\hline Risk Factors & Frequency & Percent \\
\hline Pallor & 10 & 9.8 \\
\hline Icterus & 1 & 1.0 \\
\hline Cyanosis & 0 & 0.0 \\
\hline Clubbing & 0 & 0.0 \\
\hline Oedema & 6 & 5.9 \\
\hline JVP & 2 & 2.0 \\
\hline & $\begin{array}{l}\text { cal Signs } \\
\text { mination }\end{array}$ & \\
\hline
\end{tabular}

Analysis of Blood Pressure Readings of Patients

\section{Hypertension at admission}

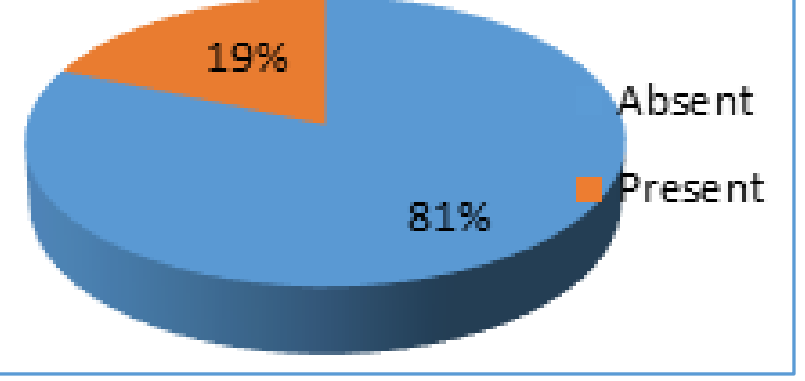

\section{total hypertensives}

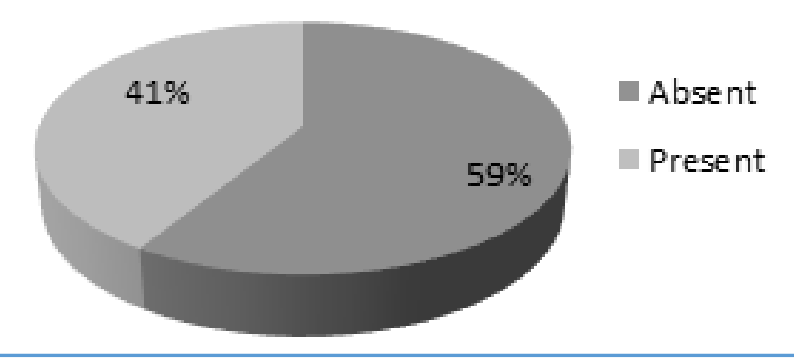

\begin{tabular}{|c|c|c|}
\hline Hypertension & Frequency & Percent \\
\hline Absent & 83 & 81.4 \\
\hline Present & 19 & 17.82 \\
\hline Total & $\mathbf{1 0 2}$ & $\mathbf{1 0 0 . 0}$ \\
\hline $\begin{array}{c}\text { Table 7. Analysis of Blood Pressure Readings of Patients } \\
\text { at the Time of Hospitalisation }\end{array}$ \\
\hline
\end{tabular}

\begin{tabular}{|c|c|c|c|c|c|}
\hline \multicolumn{6}{|c|}{ Hypertension } \\
\hline & & 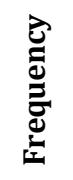 & $\begin{array}{l}\stackrel{ \pm}{0} \\
\stackrel{0}{0} \\
0\end{array}$ & 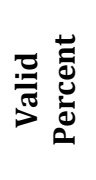 & 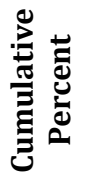 \\
\hline \multirow{3}{*}{ Valid } & Absent & 60 & 58.8 & 58.8 & 58.8 \\
\hline & Present & 42 & 41.2 & 41.2 & 100.0 \\
\hline & Total & 102 & 100.0 & 100.0 & \\
\hline
\end{tabular}

Table 8. Total Hypertensives in Study (Those Diagnosed at Admission and those who are Already on Treatment) 
Analysis of BMI in patients.

Analysis of Ankle Brachial Index in patients.

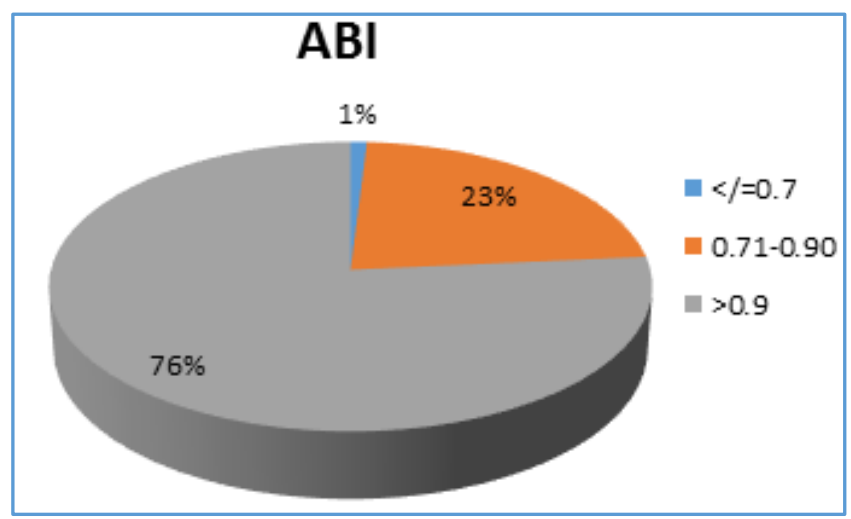

\begin{tabular}{|c|c|c|c|c|}
\hline $\bar{q}$ & 导 & 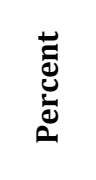 & 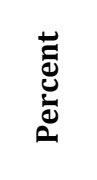 & 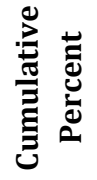 \\
\hline$</=0.7$ & 1 & 1.0 & 1.0 & 1.0 \\
\hline $0.71-0.90$ & 23 & 22.5 & 22.5 & 23.5 \\
\hline$>0.9$ & 78 & 76.5 & 76.5 & 100.0 \\
\hline Total & 102 & 100.0 & 100.0 & \\
\hline
\end{tabular}

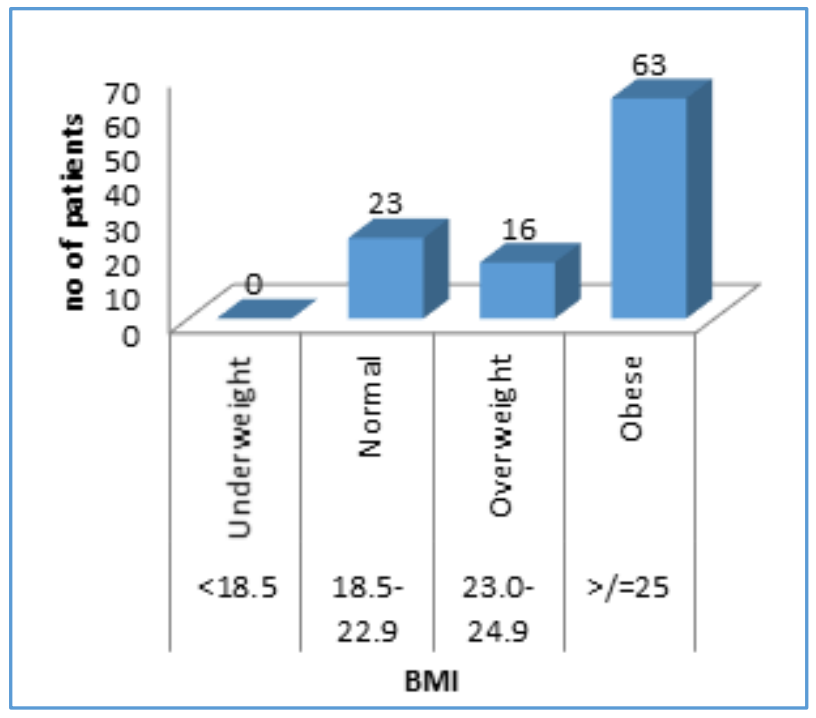

\begin{tabular}{|c|c|c|c|}
\hline BMI & Category & Frequency & Percent \\
\hline$<18.5$ & Underweight & 0 & 0.0 \\
\hline $18.5-22.9$ & Normal & 23 & 22.5 \\
\hline $23.0-24.9$ & Overweight & 16 & 15.7 \\
\hline$>/=25$ & Obese & 63 & 61.8 \\
\hline Total & \multicolumn{3}{|c|}{ Table 10. Analysis of BMI in Patients } \\
\hline \multicolumn{3}{|c|}{} \\
\hline
\end{tabular}

Analysis of Angiographic Findings in Patients

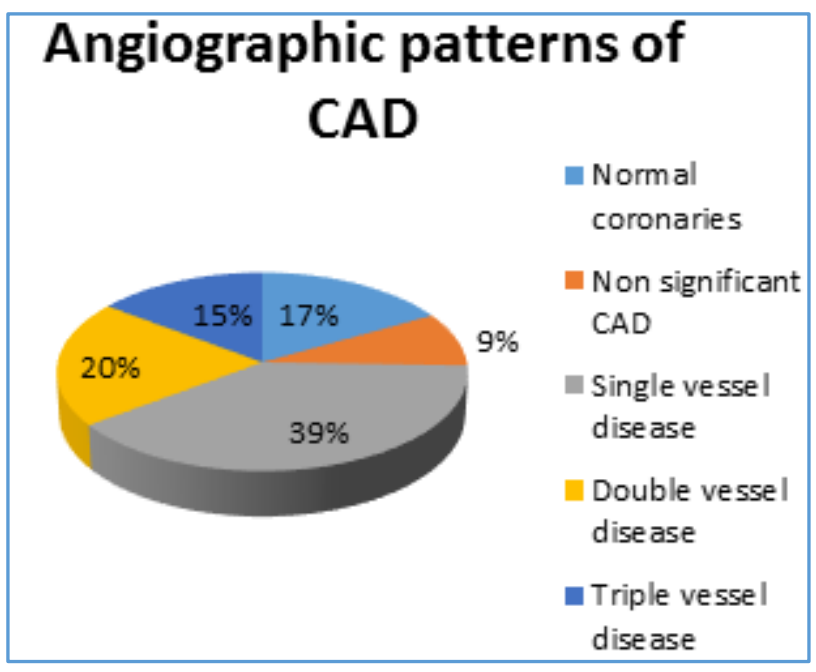

\begin{tabular}{|c|c|c|}
\hline Pattern & Frequency & Percent \\
\hline Normal coronaries & 17 & 16.7 \\
\hline Non-significant CAD & 9 & 8.8 \\
\hline Single vessel disease & 40 & 39.2 \\
\hline Double vessel disease & 21 & 20.6 \\
\hline Triple vessel disease & 15 & 14.7 \\
\hline Total & 102 & 100.0 \\
\hline
\end{tabular}

Comparison of ABI Values in Subjects with Different Patterns of Coronary Artery Disease

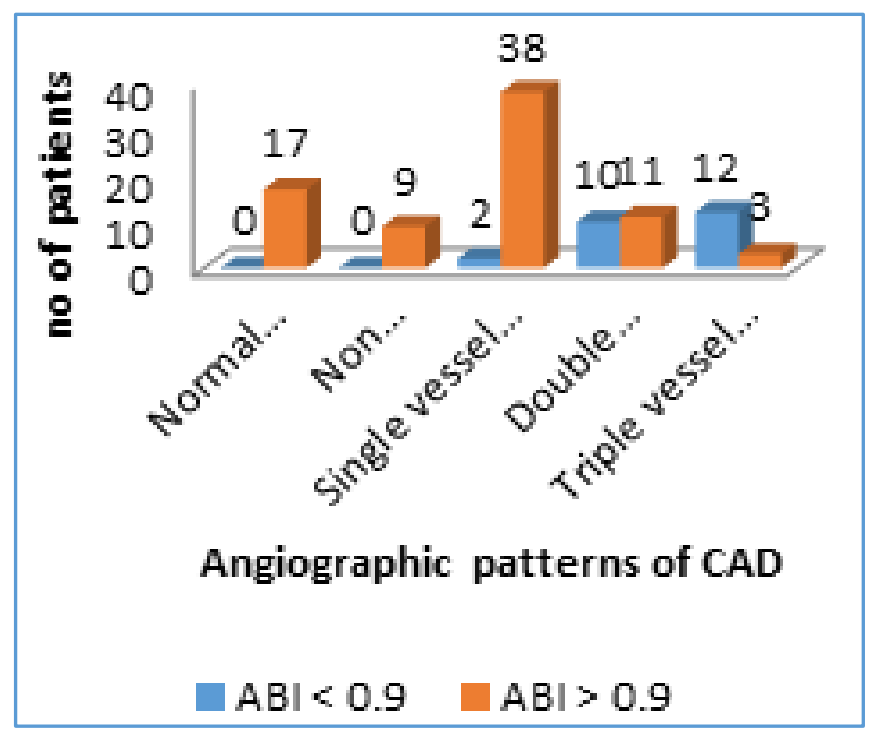

\begin{tabular}{|c|c|c|c|c|c|}
\hline $\begin{array}{c}\text { Angiographic } \\
\text { Patterns }\end{array}$ & & \multicolumn{2}{|c|}{ ABI } & \multirow{2}{*}{ Total } & $\begin{array}{c}\text { P } \\
\text { Value }\end{array}$ \\
\hline & & $</=0.9$ & $>0.9$ & & \\
\hline $\begin{array}{c}\text { Normal } \\
\text { coronaries } \\
\text { (recanalised) }\end{array}$ & $\mathrm{N}$ & 0 & 17 & 17 & \multirow{2}{*}{$<0.0001$} \\
\cline { 2 - 5 } & $\%$ & $.0 \%$ & $21.8 \%$ & $16.7 \%$ & \\
$\begin{array}{c}\text { Non- } \\
\text { significant } \\
\text { CAD }\end{array}$ & $\mathrm{N}$ & 0 & 9 & 9 & \\
\cline { 2 - 5 } & $\%$ & $.0 \%$ & $11.5 \%$ & $8.8 \%$ & \\
\hline Single vessel & $\mathrm{N}$ & 2 & 38 & 40 & \\
\hline \multicolumn{2}{c|}{} & & & & \\
\end{tabular}




\begin{tabular}{|c|c|c|c|c|c|}
\hline disease & $\%$ & $8.3 \%$ & $48.7 \%$ & $39.2 \%$ & \\
\hline \multirow{2}{*}{$\begin{array}{c}\text { Double vessel } \\
\text { disease }\end{array}$} & $\mathrm{N}$ & 10 & 11 & 21 & \\
\hline & $\%$ & $41.7 \%$ & $14.1 \%$ & $20.6 \%$ & \\
\hline \multirow{2}{*}{$\begin{array}{c}\text { Triple vessel } \\
\text { disease }\end{array}$} & $\mathrm{N}$ & 12 & 3 & 15 & \\
\hline & $\%$ & $50.0 \%$ & $3.8 \%$ & $14.7 \%$ & \\
\hline \multicolumn{2}{|l|}{$\mathrm{N}$} & 24 & 78 & 102 & \\
\hline \multicolumn{2}{|l|}{$\%$} & $100.0 \%$ & $100.0 \%$ & $100.0 \%$ & \\
\hline \multicolumn{6}{|c|}{$\begin{array}{l}\text { Table 12. Comparison of ABI Values in Subjects with } \\
\text { Different Patterns of Coronary Artery Disease }\end{array}$} \\
\hline
\end{tabular}

Pattern of Vessels involved in Study Subjects

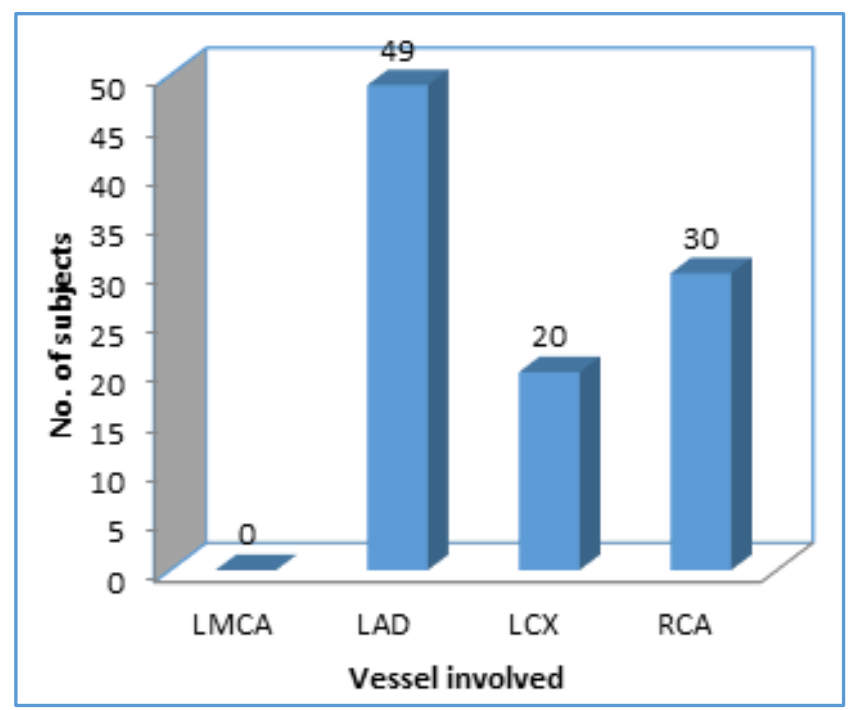

\begin{tabular}{|c|c|c|}
\hline Vessel Involved & No. of Subjects & Percentage \\
\hline LMCA & 0 & 0 \\
\hline LAD & 49 & 48.2 \\
\hline LCX & 20 & 19.6 \\
\hline RCA & 30 & 29.2 \\
\hline \multicolumn{2}{|c|}{ Table 13. Pattern of Vessels involved in Study Subjects } \\
\hline
\end{tabular}

\section{Analysis of Association of ABI with CAD}

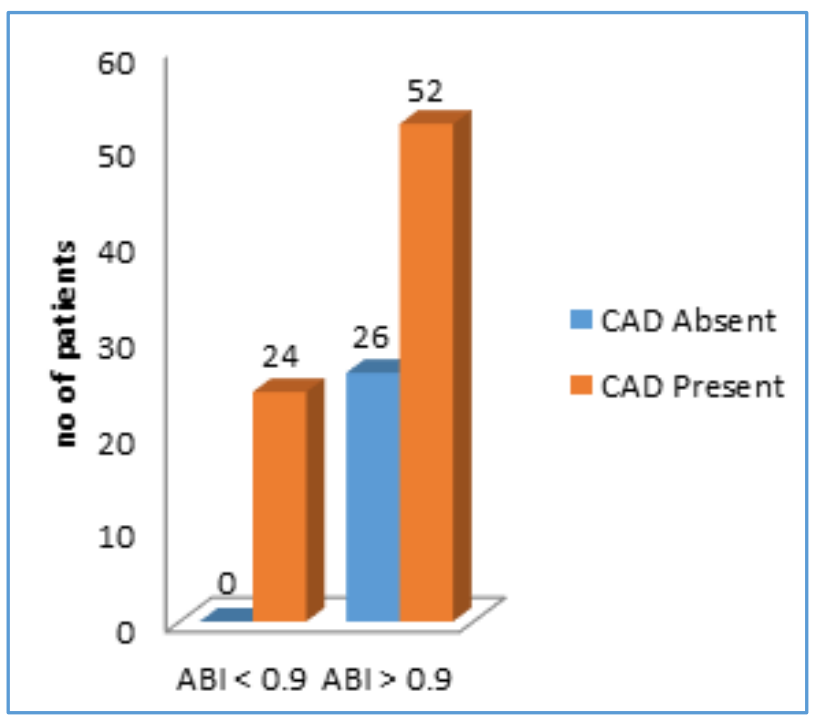

\begin{tabular}{|c|c|c|c|c|c|}
\hline \multicolumn{2}{|c|}{} & \multicolumn{2}{|c|}{ ABI } & \multirow{2}{*}{ Total } & \multirow{2}{*}{ P Value } \\
\cline { 3 - 6 } \multicolumn{2}{|c|}{} & $</=\mathbf{0 . 9}$ & $>\mathbf{0 . 9}$ & & \\
\hline \multirow{2}{*}{$\begin{array}{c}\text { CAD } \\
\text { Absent } \\
\text { Present }\end{array}$} & $\mathrm{N}$ & 0 & 26 & 26 & \multirow{2}{*}{0.001} \\
\cline { 2 - 5 } & $\%$ & $.0 \%$ & $33.3 \%$ & $25.5 \%$ & \\
\cline { 2 - 5 } & $\mathrm{N}$ & 24 & 52 & 76 & \\
\cline { 2 - 5 } Total & $\mathbf{N}$ & $\mathbf{2 4}$ & $\mathbf{7 8}$ & $\mathbf{1 0 2}$ & \\
\cline { 2 - 5 } & $\mathbf{9}$ & $\mathbf{1 0 0 . 0 \%}$ & $\mathbf{1 0 0 . 0 \%}$ & $\mathbf{1 0 0 . 0 \%}$ & \\
\hline \multicolumn{6}{|c|}{ Table 14. Analysis of Association of ABI with CAD } \\
\hline
\end{tabular}

\section{SUMMARY AND CONCLUSION}

The Following Conclusions were Drawn from the Study

1. Maximum patients were present in the age group of $41-50$ yrs., mean age being 55 years $+12.11 \mathrm{sd}$.

2. Male patients were $79.4 \%$ and $20.58 \%$ were female patients.

3. The most common symptom was chest pain, $82.35 \%$ patients had it at the time of presentation. The next frequent symptom was breathlessness, $53.92 \%$ patients had it; $42.15 \%$ patients had sweating; $24.5 \%$ patients had palpitations.

4. Among the risk factors, $41.1 \%$ had hypertension and $33.3 \%$ had sedentary lifestyle.

5. On examination $61.7 \%$ patients had obesity, defined by BMI $>25$ and a total of $41.1 \%$ patients had hypertension.

6. 24 patients had $\mathrm{ABI}<0.9$ indicating $\mathrm{PAD}$ i.e. $23.52 \%$ in the study had PAD.

7. As visualised by CAG, $39.2 \%$ patients had SVD, $20.58 \%$ patients had DVD and $14.7 \%$ had TVD; $8.8 \%$ patients had non-significant coronary artery disease; $16.66 \%$ patients had normal epicardial coronaries.

8. Among 40 patients of SVD, $2(5 \%)$ had $\mathrm{ABI}<0.9$. Among 21 patients of DVD, $11(47.6 \%)$ had $\mathrm{ABI}<0.9$. Among 15 patients of TVD, $12(80 \%)$ had ABI $<0.9$. None of the patients with non-significant coronary artery disease and normal coronaries had $\mathrm{ABI}<0.9$.

9. LAD was involved in 49 patients $(48.2 \%)$, RCA was involved in $30(29.2 \%)$ patients and LCX was involved in $20(19.6 \%)$ patients. The frequency of LAD involvement was maximum followed by RCA and then LCX.

10. $24(100 \%)$ patients who had ABI $<0.9$ also had angiographic proven coronary artery disease. Of 78 patients who had $\mathrm{ABI}>0.9,52(66.7 \%)$ patients had significant coronary artery disease. Of 76 patients of significant coronary artery disease, $24(31.5 \%)$ patients had $\mathrm{ABI}<0.9$.

\section{ABBREVIATIONS}

ABI- Ankle-Brachial Index

CAD- Coronary artery disease.

CVD- Cardiovascular disease.

CVE- Cardiovascular events.

SVD- Single Vessel Disease.

DVD- Double Vessel Disease.

TVD- Triple Vessel Disease.

PAD- Peripheral Artery Disease.

HDL- High Density Lipoprotein.

LDL- Low Density Lipoprotein.

VLD- Very Low Density Lipoprotein.

SBP- Systolic Blood Pressure.

DBP- Diastolic Blood Pressure.

BMI- Body Mass Index.

NCD- Non-Communicable Disease.

LMCA- Left Main Coronary Artery. 
LAD- Left Anterior Descending Artery.

LCX- Left Circumflex Artery.

RCA- Right Coronary Artery.

CLI- Critical Limb Ischaemia.

LEAD- Lower Limb Arterial Disease.

LMD- Left Main Disease.

PND- Paroxysmal Nocturnal Dyspnoea.

MI- Myocardial Infarction.

JVP- Jugular Venous Pressure.

\section{REFERENCES}

1. Sen K, Bonita R. Global health status: two steps forward, one step back. Lancet 2000;356(9229):577-82.

2. Global Health Observatory (GHO) data, World Health Organization (WHO), 2016.

3. Omran AR. The epidemiologic transition. A theory of the epidemiology of population change. Millbank Memorial Fund Q 1971;49(4):509-38.

4. Pearson TA, Jamison DT, Trejo-Gutierrez H. Cardiovascular disease. In: Jamison DT. edr. Disease control priorities in developing countries. New York, NY: Oxford University Press 1993:577-99.

5. Yusuf S, Reddy S, Ounpuu S, et al. Global burden of cardiovascular diseases, part 1: general considerations, the epidemiologic transition, risk factors, and impact of urbanization. Circulation 2001;104(22):2746-53. http://circ.ahajournals.org/content/104/22/2746.full

6. WHO factsheets http://www.who.int/mediacentre/factsheets/fs317/en/

7. Fact sheet, WHO. 2016.

8. Global Health Observatory (GHO) data, WHO 2016.

9. The World Health Report. Making a Difference. Geneva: World Health Organization, 1999.

10. Murray CJL, Lopez AD. The global burden of disease: a comprehensive assessment of mortality and disability from diseases, injuries, and risk factors in 1990 and projected to 2020. Boston, Mass: Harvard School of Public Health 1996.

11. Gupta R. Recent trends in coronary heart disease epidemiology in India. Indian Heart J 2008;60(2 Suppl B):B4-18.

12. Edwards WD. Anatomy of the Cardiovascular System: Clinical Medicine. Vol 6. Philadelphia, PA: Harper \& Row 1984:1-24.

13. Edwards WD. Cardiac anatomy and examination of cardiac specimens. In: Emmanouilides G, Reimenschneider T, Allen H, eds. Moss \& Adams' Heart Disease in Infants, Children and Adolescents. $5^{\text {th }}$ edn. Baltimore: Williams \& Wilkins 1995:70-105.

14. Edwards WD. Applied anatomy of the heart. In: Giuliani ER, Fuster V, Gersh BJ, et al. eds. Cardiology fundamentals and practice. Vol 1. 2nd edn. St Louis, MO: Mosby-Year Book 1991:47-112.

15. Bruschke AV, Sheldon WC, Shirey EK, et al. A half century of selective coronary arteriography. J Am Coll Cardiol 2009;54(23):2139-44.

16. Gibson CM, Cannon CP, Daley WL, et al. TIMI frame count: a quantitative method of assessing coronary artery flow. Circulation 1996;93(5):879-88.

17. Risk factors, global burden of cardiovascular medicine, Braunwald's heart disease - text book of cardiology. 9th edn. 2012.
18. Lawes CM, Vander Hoorn S, Rodgers A, et al. Global burden of blood-pressure-related disease, 2001. Lancet 2008;371(9623):1513-8.

19. Haider AW, Larson MG, Franklin SS, et al. Systolic blood pressure, diastolic blood pressure and pulse pressure as predictors of risk for congestive heart failure in the Framingham heart study. Ann Intern Med 2003;138(1):1016.

20. Bobrie G, Chatellier G, Genes N, et al. Cardiovascular prognosis of "masked hypertension" detected by blood pressure self-measurement in elderly treated hypertensive patients. JAMA 2004;291(11):1342-9.

21. Ingelsson E, Bjorklund-Bodegard K, Lind L, et al. Diurnal blood pressure pattern and risk of congestive heart failure. JAMA 2006;295(24):2859-66.

22. Nissen SE, Tuzcu EM, Libby $P$, et al. Effect of antihypertensive agents on cardiovascular events in patients with coronary disease and normal blood pressure: the CAMELOT study: a randomized controlled trial. JAMA 2004;292(18):2217-25.

23. Law MR, Wald NJ, Morris JK, et al. Value of low dose combination treatment with blood pressure lowering drugs: analysis of 354 randomised trials. BMJ 2003;326(7404):1427.

24. Ezzati M, Henley SJ, Thun MJ, et al. Role of smoking in global and regional cardiovascular mortality. Circulation 2005;112(4):489-97.

25. Balbinotto Neto G, Silva EN. The costs of cardiovascular disease in Brazil: a brief economic comment. Arq Bras Cardiol 2008;91(4):198-9, 217-8.

26. Teo KK, Ounpuu S, Hawken S, et al. Tobacco use and risk of myocardial infarction in 52 countries in the INTERHEART study: a case-control study. Lancet 2006;368(9536):64758.

27. Barnoya J, Glantz SA. Cardiovascular effects of secondhand smoke: almost as large as smoking. Circulation 2005;111(20):2684-98.

28. Jha FP, Chaloupka FJ, Moore J, et al. Tobacco addiction. In: Jamison DT, Breman JG, Measham AR, et al. eds. Disease control priorities in the developing countries. $2^{\text {nd }}$ edn. New York, Oxford University Press 2006:869-86.

29. Critchley JA, Capewell S. Mortality risk reduction associated with smoking cessation in patients with coronary heart disease: a systematic review. JAMA 2003;290(1):86-97.

30. Collins R, Armitage J, Parish S, et al. Effects of cholesterollowering with simvastatin on stroke and other major vascular events in 20,536 people with cerebrovascular disease or other high-risk conditions. Lancet 2004;363(9411):757-67.

31. Menotti A, Lanti M, Zanchetti A, et al. The Role of HDL cholesterol in metabolic syndrome predicting cardiovascular events. The gubbio population study. Nutrition, Metabolism and Cardiovascular Diseases 2011:21(5):315-22.

32. Pischon T, Girman CJ, Sacks FM, et al. Non-high-density lipoprotein cholesterol and apolipoprotein B in the prediction of coronary heart disease in men. Circulation 2005;112(22):3375-83.

33. Ridker PM, Rifai N, Cook NR, et al. Non-HDL cholesterol, apolipoproteins A-I and B100, standard lipid measures, 
lipid ratios and CRP as risk factors for cardiovascular disease in women. JAMA 2005;294(3):326-33.

34. Bansal S, Buring JE, Rifai N, et al. Fasting compared with nonfasting triglycerides and risk of cardiovascular events in women. JAMA 2007;298(3):309-16.

35. Nordestgaard BG, Benn M, Schnohr P, et al. Nonfasting triglycerides and risk of myocardial infarction, ischemic heart disease and death in men and women. JAMA 2007;298(3):299-308.

36. Ridker PM. Fasting versus nonfasting triglycerides and the prediction of cardiovascular risk: Do we heed to revisit the oral triglyceride tolerance test? Clin Chem 2008;54(1):113.

37. Booth GL, Kapral MK, Fung K, et al. Relation between age and cardiovascular disease in men and women with diabetes compared with non-diabetic people: a population-based retrospective cohort study. Lancet 2006;368(9529):29-36.

38. Centers for Disease Control and Prevention (CDC): Cigarette smoking among adults-United States, 2007. Morb Mortal Wkly Rep 2008;57(45):1221-6.

39. Wild S, Roglic G, Green A, et al. Global prevalence of diabetes: estimates for the year 2000 and projections for 2030. Diabetes Care 2004;27(5):1047-53.

40. Misr A, Khurana L. Obesity and the metabolic syndrome in developing countries. J Clin Endocrinol Metab 2008;93(11 Suppl 1):S9-30.

41. Popkin BM, Gordon-Larsen P. The nutrition transition: worldwide obesity dynamics and their determinants. Int J Obes Relat Metab Disord 2004;28(Suppl 3):S2-9.

42. Mendez MA, Monteiro CA, Popkin BM. Overweight exceeds underweight among women in most developing countries. Am J Clin Nutr 2005;81(3):714-21.

43. Poskitt EM. Countries in transition: underweight to obesity non-stop? Ann Trop Paediatr 2009;29(1):1-11.

44. Manson JE, Greenland P, LaCroix AZ, et al. Walking compared with vigorous exercise for the prevention of cardiovascular events in women. $\mathrm{N}$ Engl J Med 2002;347(10):716-25.
45. Fung TT, Malik V, Rexrode KM, et al. Sweetened beverage consumption and risk of coronary heart disease in women. Am J Clin Nutr 2009;89(4):1037-42.

46. Population reference bureau: speed of population aging in selected countries.

http://www.prb.org/Home/Publications/GraphicsBank/ Aging.aspx2009

47. Kivimaki M, Leino-Arjas $P$, Luukkonen R, et al. Work stress and risk of cardiovascular mortality: prospective cohort study of industrial employees. BMJ 2002;325(7369):857.

48. Rosengren A, Hawken S, Ounpuu S, et al. Association of psychosocial risk factors with risk of acute myocardial infarction in 11119 cases and 13648 controls from 52 countries (the INTERHEART study): case-control study. Lancet 2004;364(9438):953-62.

49. Blumenthal JA, Sherwood A, Babyak MA, et al. Effects of exercise and stress management training on markers of cardiovascular risk in patients with ischemic heart disease: a randomized controlled trial. JAMA 2005;293(13):162634.

50. Goyal A, Yusuf S. The burden of cardiovascular disease in the Indian subcontinent. Indian J Med Res 2006;124(3):235-44.

51. Ajay VS, Gupta R, Panniyammakkal J, et al. National cardiovascular disease database, Delhi Ministry of Health and Family Welfare, Government of India. Geneva, World Health Organization, 2002.

52. Yusuf S, Hawken S, Ounpuu S, et al. Effect of potentially modifiable risk factors associated with myocardial infarction in 52 countries (the INTERHEART study): casecontrol study. Lancet 2004;364(9438):937-52.

53. Lopez AD, Mathers CD, Ezzati E, et al. Measuring the global burden of disease and risk factors, 1990-2001. In: Lopez AD, Mathers CD, Ezzati E, et al. eds. Global burden of disease and risk factors, New York: Oxford University Press 2006:1-14. 